\title{
Maternal treatment of cyclic glycine-proline improves memory, astrocyte plasticity, vascularization and GluR-1 expression of adult offspring in rats
}

\author{
Gagan Singh-Mallah ${ }^{1}$, Maryam Ardalan $^{2}$, Da Kang ${ }^{1}$, Kuljeet Singh ${ }^{3}$, Chris Mcmahon ${ }^{3}$, \\ Carina Mallard ${ }^{2}$, and Jian Guan ${ }^{1}$ \\ ${ }^{1}$ The University of Auckland Faculty of Medical and Health Sciences \\ ${ }^{2}$ University of Gothenburg Sahlgrenska Academy \\ ${ }^{3}$ AgResearch Ltd Ruakura Research Centre
}

November 13, 2020

\begin{abstract}
Abstract Background and Purpose: Cyclic glycine-proline (cGP) regulates the function of insulin-like growth factor-1 (IGF-1), which is essential for post-natal brain development and adult cognitive function. We evaluated the efficacy of maternally administered cGP on spatial memory and the association with astrocytic plasticity, vascularization and synaptic expressions in the hippocampus of their adult offspring. Experimental Approach: Either cGP or saline was orally administered to Sprague Dawley dams from post-natal days 8-22. Spatial memory was evaluated using Morris Water Maze tests between post-natal days 70-75. Using immunohistochemistry and stereological analysis, we evaluated capillary density, astrocytic processes and expression of synaptophysin and glutamate receptor-1 (GluR-1) in the CA1 stratum-radiatum of the hippocampus. Key Results: Compared to the saline-treated offspring, cGP-treated offspring showed higher path efficiency of entry to the platform zone ( $\mathrm{p}=0.03)$ and lower average heading errors to the platform zone $(\mathrm{p}=0.02)$. Astrocyte processes of cGP-treated offspring were longer and larger with more branches $(\mathrm{p}=0.03-0.0001)$ than saline-treated offspring. The density of capillaries $(\mathrm{p}=0.007)$ and GluR-1 ( $\mathrm{p}=0.02)$ were also higher in cGP-treated offspring. The average heading error was negatively correlated with the length ( $\mathrm{r}=-0.69)$, volume $(\mathrm{r}=-0.72)$ and number of astrocytic branches $(\mathrm{r}=-0.65)$. Independent of treatment, the changes of astrocyte processes were positively correlated with the density of capillaries $(\mathrm{r}=0.73-0.78)$ and expression of GluR-1 ( $\mathrm{r}=0.66-0.68)$. Conclusion and Implications: The improved spatial memory of cGP-treated offspring after post-natal maternal administration may be mediated via promoting astrocytic plasticity, vascularization and glutamate trafficking. Therefore, cGP may have a role in regulating IGF-1 function during brain development.
\end{abstract}

\section{Hosted file}

Manuscript.pdf available at https://authorea.com/users/375459/articles/492697maternal-treatment-of-cyclic-glycine-proline-improves-memory-astrocyte-plasticityvascularization-and-glur-1-expression-of-adult-offspring-in-rats

\section{Hosted file}

Figures.pdf available at https://authorea.com/users/375459/articles/492697maternal-treatment-of-cyclic-glycine-proline-improves-memory-astrocyte-plasticity-

vascularization-and-glur-1-expression-of-adult-offspring-in-rats 